\title{
Comparing Model and Experimental Results of the Volume of Filtrate during Sludge Dewatering
}

\author{
Sheikh Yusuf, Joel Ademiluyi \\ Department of Civil Engineering, University of Nigeria, Nsukka, Nigeria \\ Email: ibnyusuff2005@yahoo.com, Professorademiluyi@yahoo.com
}

How to cite this paper: Yusuf, S. and Ademiluyi, J. (2018) Comparing Model and Experimental Results of the Volume of Filtrate during Sludge Dewatering. Open Access Library Journal, 5: e4650. https://doi.org/10.4236/oalib.1104650

Received: May 8, 2018

Accepted: July 6, 2018

Published: July 9, 2018

Copyright (C) 2018 by authors and Open Access Library Inc.

This work is licensed under the Creative Commons Attribution International License (CC BY 4.0).

http://creativecommons.org/licenses/by/4.0/

\section{(c) (i) Open Access}

\begin{abstract}
The results of the experiment of dewatering analysis carried out on a municipal sludge were recorded. Similarly, analytical mathematics was used to develop an equation to calculate volume of filtrate. The two results were plotted in graphs and comparisons were made. The results show very close relationships between the two results. In fact in most cases the two results were almost overlapping. For example after 3, 6, 9, 12, 15 hours, the volumes of filtrates are: $0.0037 \mathrm{~m}^{3}$ (model), $0.004 \mathrm{~m}^{3}$ (experiment), 0.005 (model), 0.0055 (experiment), 0.006 (model), 0.0067 (experiment), 0.0066 (model), 0.0065 (experiment) and 0.0065 (model), 0.0064 (experiment). This has shown that the experiment was carried out very well and that, mathematical equations can be used directly in order to calculate the volume of filtrate and the values can be nearly the same with model results.
\end{abstract}

\section{Subject Areas \\ Civil Engineering}

\section{Keywords}

Municipal Sludge, Dewatering, Volume of Filtrate, Analytical Mathematics

\section{Introduction}

\subsection{Wastewater}

Wastewater can have a number of definitions. Domestic wastewater is defined as wastewater from household water use, while industrial wastewater is from industrial practices only. In reality, the term "wastewater" clearly encompasses domestic, commercial, industrial, agricultural components and also faecal sludge, 
these are sometimes covered separately in order to clarify or highlight the importance of the individual components or wastewater streams [1]. The presence of contaminants in sewage sludge arising from municipal discharges is the most challenging problem and may be the deciding factor in determining the choice of a utilization dewatering option [2].

\subsection{Sludge}

Sludge is a semi-solid material produced by various biological and chemical processes in water and wastewater treatment plants that needs further treatment prior to its disposal into the environment. More importantly, the water in sludge is not only in one form in terms of its binding characteristics to solids. According to [3] the form of water in sludge determines the effectiveness of sludge treatment operations to separate the water associated with the solids. Municipal sludge can be obtained from open drains, while in some cases sludge originates from the process of treatment of wastewater and is separated from the treatment process by sedimentation or flotation. Sewage sludge consists of water and solids that can be divided into mineral and organic solids. The fact remain that a simple technique close to nature and very effective in wastewater treatment is dewatering in drying beds. Reference [4], the principal advantages of drying beds are low costs, infrequent attention required, and high solids content in the dried product, especially in arid climates. The main purpose of a drying bed is to achieve dewatering; i.e. a physical separation between liquid and solids.

\section{Literature Review}

\subsection{Sludge Dewatering}

The form of water in sludge determines the effectiveness of sludge treatment operations to separate the water associated with the solids. Before ultimate disposal, the water content of sludge should be decreased both from environmental and economical point of view [5]. Sludge dewatering, commonly achieved through vacuum/pressure filtration or centrifugation, is a paramount process in water and wastewater treatment systems as it reduces the volume of sludge, and consequently, the costs for transporting the sludge to its ultimate disposal site. Cake filters commonly used in wastewater treatment works include pressure filters, vacuum filters and centrifugal filters [6]. In this research however, no pump is used, rather the sludge is allowed to percolate onto a filter made of sand and gravel. The characterization of the sludge to be dewatered is the key factor for the design and operation of sludge filters [4]. The problem of sludge generation, storage, treatment and disposal is a serious one especially in developing countries where there are no enough sewers or even none in most of our cities, and the wastewater is not treated accordingly. Therefore the collection, treatment and disposal of sludge is an issue that is supposed to be taken serious especially if one look at the hazards involved in terms of degradation of the environment and spreading of waterborne diseases [7]. Sludge filtration theories and derived 
equations have been made on experimental assumptions and conditions. Reference [2], each researcher is making effort to modify already existing theory in order to introduce a completely new concept for evaluating sludge filtration equation. A careful study of researchers works on this topic, have shown that most of them do refer to Carman's equation as the basis of their research.

\subsection{Filtration Theories}

\subsubsection{Filtration Based on Cake Resistance}

This was pioneered by Almy and Lewis [6] that was in 1912 when they filtered chromium hydroxide. They suggested this equation:

$$
\frac{\mathrm{d} v}{\mathrm{~d} t}=k p^{n} / V^{m}
$$

This constituted the basic law of filtration, where $m$ and $n$ are indefinite powers of the relationships, which the rate of flow $\frac{\mathrm{d} v}{\mathrm{~d} t}$ possesses with pressure $P$ and volume $V$ respectively. Since Poiseuille's law and Darcy's law both deal with flow and considering sand bed as a bundle of capillaries, Carman proposed the following equation:

$$
t=\frac{V^{2} C \mu_{r}}{2 P A^{2}}+\frac{\mu R V}{P A}
$$

\subsubsection{Modification of Carman's Equation}

Reference [6], in 1974, Anazodo objected to Carman's equation on its formulation point of view. He argued that the approximation of compressible filter cakes to rigid bundles of capillary tubes or to non-compressible sand-bed did not make sense. He then used dimensionless analysis to come up with the following equation:

$$
V=\frac{A^{2} C r}{C r} \frac{A^{\frac{1}{2}} p C^{\frac{1}{2}} r^{\frac{1}{2}} t}{\mu} f
$$

Since the relationship between $V$ and $t$ has been established to be parabolic, Anazodo substituted $f=1 / 2$ to obtain this equation:

$$
V^{2}=\frac{P A^{5} / 2 t}{\mu C^{\frac{1}{2}} r^{\frac{1}{2}}}
$$

Reference [6] reported that Gale and White advocated that Anazodo's partial equation should be written as:

$$
V^{2}=P \mu^{-1} A^{2 b t} C r^{2 b-3}
$$

So that relationship between $V$ and $A$ should be experimentally determined. Reference [8], conducted an investigation to determine experimentally the values of the exponent " $b$ " which relates the volume of filtrate to the area of filtration. They suggested that the total area of filtration should be used in Carman's equation, while the effective area of filtration should be used in the dimensional 
equation for sludge filtration. They came up with these equations:

$$
V^{2}=\frac{P A t 1.82 t}{\mu C r 1.18}
$$

and

$$
V^{2}=\frac{P A^{2} e f f 2.76 t}{\mu(C r) 0.24}
$$

\subsubsection{Theory Based on Filtration Coefficient}

Halff on his own part developed an equation that established the fact that filtration follows the parabolic relationship until the cake reaches $80 \%$ filtration [6]. He proposed this equation:

$$
C f_{i}=\frac{\delta \gamma i}{\mu(C o) S}
$$

\subsubsection{Theory Based on the Concept of SDN}

Even though the specific resistance parameter is a good measure of sludge filtrability, it does not have constant unit. In the light of the above, a dimensionless number referred to as the sludge dewaterability number was developed by [8], and it has found to be a very good measure of sludge filtrability. It is given as:

$$
\frac{\Delta H\left(C_{o}-C_{f}\right)}{V t C c}+\frac{H_{0}}{V t}
$$

where:

$C c=$ Concentration of cake $\left(\mathrm{kg} / \mathrm{m}^{3}\right)$

$C_{f}=$ Concentration of filtrate $\left(\mathrm{kg} / \mathrm{m}^{3}\right)$

$C_{o}=$ Concentration of sludge $\left(\mathrm{kg} / \mathrm{m}^{3}\right)$

$H_{0}=$ Initial headloss $(\mathrm{m})$

$\Delta H=$ Change in headloss (m)

SDN $=$ Sludge Dewaterability Number

$t=$ Time of filtration

$V=$ Volume of filtration $\left(\mathrm{m}^{3}\right)$

\subsubsection{Resistance to Filtration}

The filtration equation according to [9]:

$$
\frac{Q}{A}=\frac{\Delta P}{\mu\left(R_{f}+\alpha c V / A\right)}
$$

considers the overall resistance to flow of filtrate to be made up of contributions from the filter medium $R_{f}$ and from the cake with specific resistance $\alpha$. Normally $R_{f}$ is found to depend on the operating pressure; the two intercepts may correspond to different values of $R_{f}$ at the two pressures. Although these porosities and permeabilities are of unused materials, the relative values may be useful for comparing behaviors under filtration conditions. Permeability $K_{p}$ normally is the property reported rather than the resistivity that has been discussed here. It is 
defined by the equation

$$
\frac{Q}{A}=K_{p} \Delta P / \mu L
$$

where $L$ is the thickness. Thus the resistivity of the medium includes its thickness.

The relation of the above equation to resistivity is:

$$
R_{f}=\frac{L}{K_{p}}
$$

\subsubsection{Theory of Filtration}

Reference [10] as filtration proceeds, a porous cake of solid particles is built up on a porous medium, usually a supported cloth. Because of the fineness of the pores the flow of liquid is laminar so it is represented by the equation

$$
Q=\frac{\mathrm{d} V}{\mathrm{~d} t}=\frac{A \Delta P}{\mu R}
$$

The resistance $R$ is made up of those of the filter cloth $R_{f}$ and that of the cake $R$, which may be assumed proportional to the weight of the cake. Accordingly:

$$
Q=\frac{\mathrm{d} V}{\mathrm{~d} t}=\frac{A \Delta P}{\mu\left(R_{f}+R_{c}\right)}
$$

where:

$$
\begin{aligned}
& c=\text { wt of solids/volume of liquid }\left(\mathrm{kg} / \mathrm{m}^{3}\right) \\
& \mu=\text { viscosity }\left(\mathrm{N} \mathrm{sec} / \mathrm{m}^{2}\right) \\
& P=\text { pressure difference }\left(\mathrm{N} / \mathrm{m}^{2}\right) \\
& A=\text { filtering surface }\left(\mathrm{m}^{2}\right) \\
& V=\text { volume of filtrate }\left(\mathrm{m}^{3}\right) \\
& Q=\text { rate of filtrate accumulation }\left(\mathrm{m}^{3} / \mathrm{sec}\right) .
\end{aligned}
$$

At constant pressure Equation (2.13) is integrated as:

$$
\frac{A \Delta P}{\mu} t=R_{f} V+\frac{\alpha C}{2 A} V^{2}
$$

The above equation can be written in linear form as:

$$
\frac{t}{V / A}=\frac{\mu}{\Delta P} R_{f}+\frac{\mu \alpha C}{2 \Delta P} \frac{V}{A}
$$

The constants $R_{f}$ and a derivable from the intercept and slope of the plot of $t / V$ against $V$. If the constant pressure period sets in when $t=t_{0}$ and $V=V_{0}$, the equation becomes:

$$
\frac{t-t_{0}}{V-V_{0}}=\frac{\mu}{A \Delta P} R_{f}+\frac{\mu \alpha C}{2 A^{2} \Delta P}\left(V+V_{0}\right)
$$

At a constant rate of filtration Equation (2.16) can be written as:

$$
Q=\frac{V}{t}=\frac{A \Delta P}{\mu\left(R_{f}+\alpha c V / A\right)}
$$


The above equation can be re-arranged in linear form as follows:

$$
\frac{\Delta P}{Q}=\frac{\Delta P}{V / t}=\frac{\mu}{A} R_{f}+\frac{\mu \alpha c}{A^{2}} V
$$

The constants again are found from the intercept and slope of the linear plot of $\Delta P / Q$ against $V$. After the constants have been determined, Equation (2.18) can be employed to predict filtration performance under a variety of constant rate conditions. For instance, the slurry may be charged with a centrifugal pump with a known characteristic curve of output pressure against flow rate [9].

\section{Methodology}

In order to carry out this research work, sewage sludge was collected from an open unlined drain along Layin Wanki in Unguwar Sarki area, Kaduna, Kaduna North Local Government of Kaduna State. The sample was collected equally along the length of the open drain in order to get a composite sample. Even though it is a municipal wastewater, but there is need to mention that there are people along the street, who are engaged in washing of clothes, locally. The wastewater from their activities is also included in this sludge. About 15 litres of sludge was poured on to the drying bed which was located on a corridor of the Water Laboratory of the Department of Civil Engineering Kaduna Polytechnic, Kaduna The drying bed was made with a glass so that it is transparent. The length is $1.5 \mathrm{~m}$ and width is 0.5 metres. The filter medium consists of coarse sand and gravel. The sand has a depth of $0.3 \mathrm{~m}$ and the same depth is the gravel $(0.3 \mathrm{~m})$. The depth above the sand (where the sludge is slowly allowed in) is 0.2 $\mathrm{m}$. In this research, the wastewater was allowed to percolate onto the drying bed for 15 days, and the volume of the filtrate was taken (and recorded) after every 24 hours, throughout the duration. From the results obtained, the $t / v$ was calculated and a graph of volume $V$ and $t / v, V$ and $t$ were plotted. A sand layer is placed on top of the gravel. The sand layer enhances drainage and prevents clogging, as it keeps the sludge from lodging in the pore spaces of the gravel. The diameter of the sand is crucial as sand with a larger diameter $(1.0-1.5 \mathrm{~mm})$ can result in the relatively fast accumulation of organic matter, thereby increasing the risk of clogging, In order to reduce this risk a sand with a smaller diameter $(0.1-0.5 \mathrm{~mm})$ is use. The municipal sludge was passed through the filter in order to get a dry solid known as cake.

The mathematical equation will be developed using advanced calculus [11]. In order to develop equation for the volume of filtrate collected $V_{f}$ there is need to refer to [12], which is:

$$
V_{f} \frac{\mathrm{d} C}{\mathrm{~d} t}=Q_{0} C_{0}-Q C_{f}
$$

where $Q_{0}$ is the rate of sludge flow $\left(\mathrm{m}^{3} / \mathrm{sec}\right)$

$Q$ is the rate of volumetric increase of the filtrate $\left(\mathrm{m}^{3} / \mathrm{sec}\right)$

$C_{0}$ is the concentration of the sludge $\left(\mathrm{kg} / \mathrm{m}^{3}\right)$ 
$C_{f}$ is the concentration of the filtrate $\left(\mathrm{kg} / \mathrm{m}^{3}\right)$

$\mathrm{d} C$ is the small change in the cake concentration $\left(\mathrm{kg} / \mathrm{m}^{3}\right)$

$V_{f}$ is the volume of fitrate in $\mathrm{m}^{3}$

\section{Volume of Filtrate Equation $\left(V_{f}\right)$}

Considering a situation where sludge is applied on the surface of filter and it was dewatered. If $Q$ and $C_{f}$ are considered to be functions of time while $C_{0}, Q_{0}$ are considered to be constant, then integrating, Equation (3.0), we will have:

$$
\int V_{f} \mathrm{~d} C=\int\left(Q_{0} C_{0}-Q C_{f}\right) \mathrm{d} t
$$

If $V_{f}$ is considered to be constant, after final collection, then Equation (3.1) becomes:

$$
V_{f} \int \mathrm{d} t=Q_{0} C_{0} \int \mathrm{d} t-\int Q(t) C_{f}(t) \mathrm{d} t
$$

But according to [12]

$$
V_{f}=Q t
$$

Therefore Equation (3.2), becomes:

$$
V_{f} \int \mathrm{d} C=Q_{0} C_{0} \int \mathrm{d} t-\int \frac{V_{f}}{t} C_{f}(t) \mathrm{d} t
$$

Integrating Equation (3.3), Equation (3.4) will be:

$$
V_{f} C=Q_{0} C_{0} t-V_{f} \int \frac{1}{t} C_{f}(t) \mathrm{d} t
$$

Integrating by part: $\frac{1}{t}=\mathrm{d} V, U=C_{f}(t), V=\log (t), \mathrm{d} u=\mathrm{d} C_{f}(t)$

Therefore: $u v-\int v \mathrm{~d} u$

$$
\begin{aligned}
& V_{f} C=Q_{0} C_{0} t-V_{f}\left[C_{f}(t) \cdot \log (t)-\int \log (t) \cdot \mathrm{d} C_{f}(t) \mathrm{d} t\right] \\
& V_{f} C=Q_{0} C_{0} t-V_{f} C_{f}(t) \cdot \log (t)-V_{f} \int \log (t) \cdot \mathrm{d} C_{f}(t) \mathrm{d} t
\end{aligned}
$$

Neglecting rate of change in $C_{f}$, Equation(3.6), becomes:

$$
V_{f} C=Q_{0} C_{0} t-V_{f} C_{f}(t) \log (t)
$$

But [12], said:

$$
Q_{0} t=V_{0}
$$

Therefore Equation (3.6) becomes:

$$
V_{f} C=V_{0} C_{0}-V_{f} C_{f}(t) \log (t)
$$

Re-organizing the above equation, Equation (3.7) becomes:

$$
V_{f}\left(C+C_{f}(t) \log (t)\right)=V_{0} C_{0}
$$

Since according to [12]:

$$
V_{0}=V_{f}+V_{c}
$$

Therefore 


$$
V_{f}\left(C+C_{f}(t) \log t\right)=C_{0}\left(V_{f}+V_{c}\right)
$$

Re-organizing the above equation, Equation (3.9), will be :

$$
\begin{gathered}
\left(C+C_{f}(t) \log (t)\right)=C_{0}\left(V_{f}+V_{c}\right) / V_{f} \\
C V_{f}=C_{0}\left(V_{f}+V_{c}\right)-C_{f}(t) \log (t) \\
C V_{f}=C_{0} V_{f}+C_{0} V_{c}-C_{f}(t) \log (t) \\
C V_{f}-C_{0} V_{f}=C_{0} V_{c}-C_{f}(t) \log (t) \\
V_{f}\left(C-C_{0}\right)=C_{0} V_{c}-C_{f}(t) \log (t) \\
V_{f}=C_{0} V_{c}-C_{f}(t) \log (t) /\left(C-C_{0}\right) \\
V_{f}=C_{0} V_{c}-C_{f}(t) \log (t) /\left(C-C_{0}\right)
\end{gathered}
$$

\section{Discussions of Results}

Considering the graphs plotted in Figures 1-3, it can be observed that the differences between the model and experimental results are so near to each other, and in fact in Figure 2, the two results overlapped. This indicates the nearness of the two results and confirmed that, one can either use the model or experiment way to get a good result of volume of filtrate. The results obtained from the research work have indicated a very good arrangement of the filter. Also the practical work was monitored efficiently. These two events made the work very successful, thus giving a very good result (Tables 1-3).

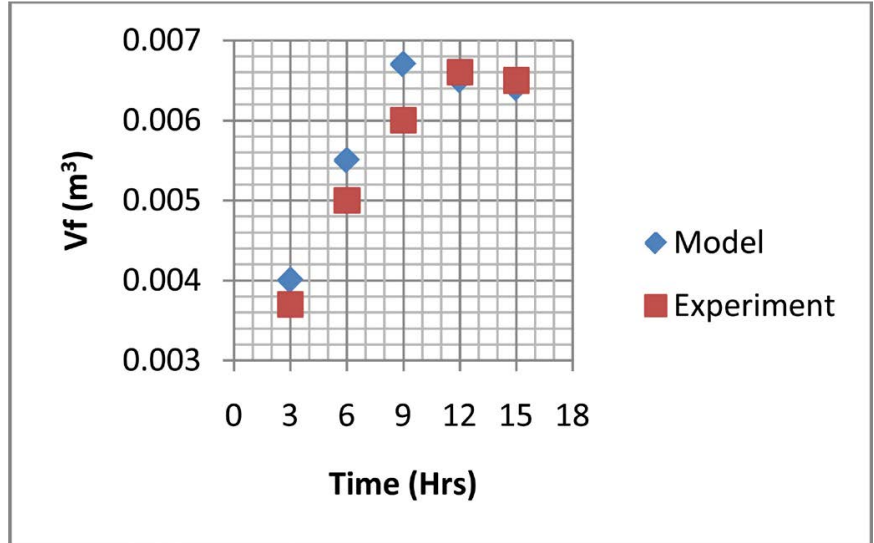

Figure 1. Time vs $V_{f}$

Table 1. Time versus model and experimental $V_{f}$

\begin{tabular}{ccc}
\hline Time & $V_{f}$ (Model) & $V_{f}$ (Experimental) \\
\hline 3 & 0.0037 & 0.004 \\
6 & 0.005 & 0.0055 \\
9 & 0.006 & 0.0067 \\
12 & 0.0066 & 0.0065 \\
15 & 0.0065 & 0.0064 \\
\hline
\end{tabular}




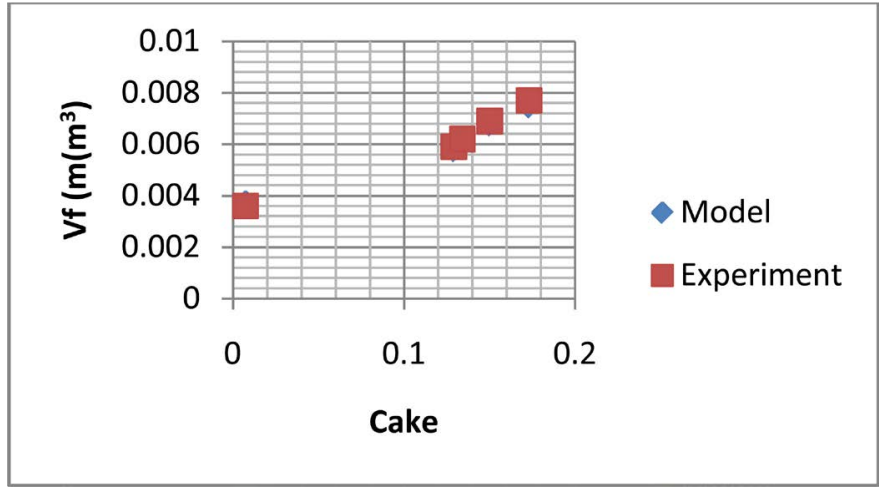

Figure 2. Cake versus $V_{f}$

Table 2. Cake versus model and experimental $V_{f}$

\begin{tabular}{ccc}
\hline Cake & $V_{f}$ (Model) & $V_{f}$ (Experimental) \\
\hline 0.0074 & 0.0037 & 0.0036 \\
0.129 & 0.0058 & 0.0059 \\
0.134 & 0.006 & 0.0062 \\
0.15 & 0.0068 & 0.0069 \\
0.173 & 0.0075 & 0.0077 \\
\hline
\end{tabular}

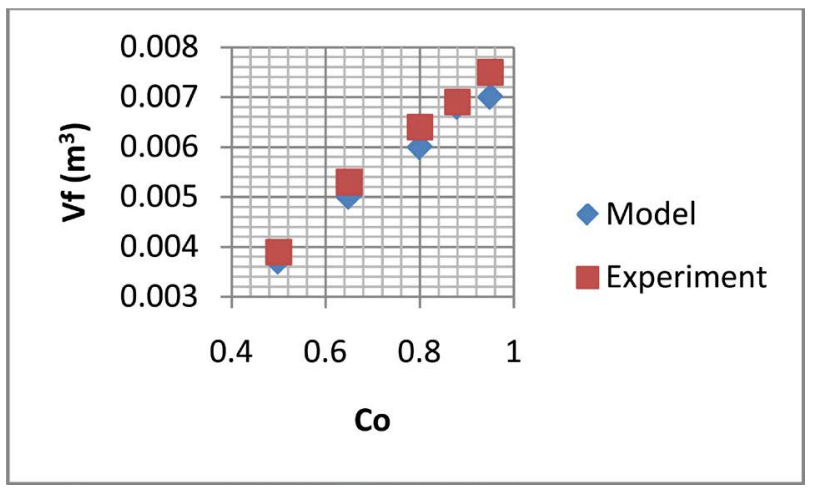

Figure 3. Concentration versus model and experimental $V_{f}$

Table 3. Concentration versus model and experimental $V_{f}$

\begin{tabular}{ccc}
\hline Co & $V_{f}$ (Model) & $V_{f}($ Experimental $)$ \\
\hline 0.5 & 0.0037 & 0.0039 \\
0.65 & 0.005 & 0.0053 \\
0.8 & 0.006 & 0.0064 \\
0.88 & 0.0068 & 0.0069 \\
0.95 & 0.007 & 0.0075 \\
\hline
\end{tabular}

\section{Conclusion and Recommendation}

\subsection{Conclusion}

The analysis carried out in this research has shown that mass balance equation 
can be used in order to develop an equation for the volume of filtrate. Also good and reliable laboratory work can lead to a good result. This can be concluded by comparing the model and experimental results that are almost the same.

\subsection{Recommendation}

From the laboratory analysis, it can be recommended that:

1) The medium of the dry bed filter should be arranged in such a way to avoid clogging within a short time; because this will make the dewatering process to be delayed and cost more, as the filter has to be cleaned within a short period of time.

2) Drops of filtrate should be monitored properly at every time. This will help to monitor the efficiency of the filter.

3) The process should be carried out in-doors to avoid external forces, such as wind that may blow away the drops from entering the collecting vessel.

4) More research should be carried out where period of filtration is increased and the time interval of recording the filtrate is decreased. For example the dewatering process can be increase to a month and the recording time be made after 12 hours. The process should be monitored to see whether it is more efficient, than the one carried out in this research.

\section{References}

[1] Corcoran, E., Nellemann, C., Baker, E., Bos, R., Osborn, D. and Savelli, H. (Eds.) (2010) Sick Water? The Central Role of Wastewater Management in Sustainable Development. A Rapid Response Assessment. UNEP/UNHABITAT.

[2] Ademiluyi, J.O. and Arimieari, L.W. (2012) Evaluating the Specific Resistance of Conditioned Sludge Filtration of Natural Driving Bed. International Journal of Current Research, 4, Issue 02.

[3] Metcalf \& Eddy, Inc. (2003) Wastewater Engineering: Treatment, Disposal, Reuse. McGraw-Hill, New York.

[4] Koné, D., Cofie, O., Zurbrügg, C., Gallizzi, K., Moser, D., Drescher, S. and Strauss, M. (2007) Helminth Eggs Inactivation Efficiency by Faecal Sludge Dewatering and Co-Composting in Tropical Climates. Water Research, 41, 4397-4402. https://doi.org/10.1016/j.watres.2007.06.024

[5] Tchobanoglous G, Burton, F.L. and Stewel, H.D. (2002) Wastewater Engineering: Treatment and Cause. 4th Edition/Revised. McGraw-Hill, New York.

[6] Ademiluyi, J.O. (1986) Developments in the Constant Vacuum Cake Filtration Theory. Paper presented at the Engineering Section of the Science Association of Nigeria Conference, 6-9 April 1986. University of Lagos.

[7] Huisman, L. and Wood, W.E. (1974) Slow Sand Filtration (Vol. 16). World Health Organization, Geneva.

[8] Ademiluyi, J.O., Egbuniwe, N. and Agunwamba, J.C. (1987) Dimensionless Number as an Index of Sludge Dewatering. Journal of Engineering for Development, 4, 2-4.

[9] Tiller, F.M. (1978) Theory and Practice of Solid-Liquid Separation. University of Houston, Houston.

[10] Ademiluyi, J.O. (1990) Effect of Shear, Filter Medium, Sludge Ageing and Sequence of Chemical Addition of Sludge Dewaterability Number (SDN). AJST Series A, 8 , No. 2. 
[11] Bird, J. (2007) Engineering Mathematics. 5th Edition, Newnes, Linacre House, Jordan Hill, Oxford, UK.

[12] Ademiluyi, J.O., Agunwamba, J.C. and Egbuniwe, N. (1989) Mass Balance Filtration Equation. Waste Management, 9, 141-149. 